\title{
Feed delivery method affects the learning of feeding and competitive behavior in dairy heifers
}

\author{
A. M. Greter, ${ }^{\star}$ K. E. Leslie,† G. J. Mason, $\ddagger$ B. W. McBride, $\ddagger$ and T. J. DeVries*1 \\ *Department of Animal and Poultry Science, University of Guelph, Kemptville Campus, 830 Prescott Street, Kemptville, ON, K0G 1J0, Canada \\ †Department of Population Medicine, Ontario Veterinary College, and \\ ‡Department of Animal and Poultry Science, University of Guelph, 50 Stone Rd. E, Guelph, ON, N1G 2W1, Canada
}

\section{ABSTRACT}

The objective of this study was to determine how different feeding methods may affect the learning of feeding, sorting, and competitive behavior of growing dairy heifers. We hypothesized that heifers previously fed a total mixed ration (TMR) would distribute their feeding time more evenly throughout the day, sort the new ration less, compete less for feed, maintain a more solid fecal consistency, and continue to grow rapidly compared with heifers previously fed a top-dressed ration (TDR). Thirty-two Holstein heifers $(237.2 \pm 21.9$ d of age) were divided into 8 groups of 4 and exposed to 1 of 2 treatments for 13 wk: 1) TMR or 2) TDR, with each containing $65 \%$ grass/alfalfa haylage and $35 \%$ textured concentrate on a dry matter (DM) basis. Following this feeding period, all heifers were switched to an unfamiliar TMR containing $56.1 \%$ grass/alfalfa haylage, $21.0 \%$ corn silage, $21.0 \%$ high-moisture corn, and $1.9 \%$ mineral supplement (DM basis) for $7 \mathrm{wk}$. Group DM intakes were recorded daily throughout the experiment. Feeding behavior, recorded using timelapse video, and sorting behavior were measured for $7 \mathrm{~d}$ during wk 1, 4, and 7 after the dietary change. Feeding competition was measured on d 2, 4, and 6 of each recording week. Sorting activity was determined through particle size analysis of the fresh feed and orts. The particle size separator separated feed into 4 fractions (long, medium, short, and fine). Sorting of each fraction was calculated as actual intake expressed as a percentage of predicted intake. Animals were scored for fecal consistency twice weekly, using a scale from 1 (liquid) to 4 (solid). Heifers were weighed every 2 wk. Neither DM intake $(9.0 \mathrm{~kg} / \mathrm{d})$ nor average daily gain $(1.2 \mathrm{~kg} / \mathrm{d})$ differed between treatments. Sorting also did not differ between treatments. Heifers tended to spend more time feeding if they had previously been fed a TDR (198.8 vs. $186.8 \mathrm{~min} / \mathrm{d}$ ). As they had done before the dietary change, heifers previously fed the

Received December 7, 2009.

Accepted March 25, 2010.

${ }^{1}$ Corresponding author: tdevries@kemptvillec.uoguelph.ca
TDR spent more time at the bunk in the $2 \mathrm{~h}$ following feed delivery (40.6 vs. $25.9 \mathrm{~min} / \mathrm{d}$ ). Heifers previously fed the TDR were displaced from the feed bunk more frequently than heifers previously fed the TMR (23.0 vs. 13.1 times/d), particularly during the 2 -h period following feed delivery. Fecal scores were lower (more fluid in consistency) for heifers originally fed the TDR (3.2 vs. 3.7). The continued difference in feed bunk competition suggests that heifers previously fed the TDR had learned these patterns in the past, retaining them even when switched to an unfamiliar ration. Furthermore, lower fecal scores for heifers previously fed the TDR suggest altered rumen fermentation, possibly because of altered diurnal consumption patterns. These results show that feeding a TMR to replacement dairy heifers from a young age promotes a more even diurnal feeding pattern, minimizes feed bunk competition, and promotes a more solid fecal consistency.

Key words: feed behavior, delivery method, competitive behavior, dairy heifer

\section{INTRODUCTION}

Learning and development of feeding behavior patterns occurs in animals as a result of experience with different foods, including postingestive feedback (Burritt and Provenza, 1990; Provenza, 1995), as well as through social interactions (Ralphs et al., 1994). Researchers have also shown that animals learn dietary patterns and habits from a young age (Provenza and Balph, 1987). For example, Nolte et al. (1990) demonstrated that young lambs exposed to wheat for 60 $\mathrm{d}$ showed a later preference for wheat when offered a choice between wheat and barley. This suggests that lambs exposed to a food early in life may have learned from the feeding event, reinforced by the positive experience of ingesting a palatable and nutritious food, resulting in continued ingestion of that familiar food. Given that this type of learning may occur from a young age and that animals prefer to consume familiar foods in familiar situations (Arnold and Maller, 1977), it follows that animals may acclimate more readily to a 
new ration when presented with feed in a form similar to that experienced as a young animal.

Adult dairy cattle often exhibit feeding behaviors that may be undesirable, such as feed sorting (Leonardi and Armentano, 2003; DeVries et al., 2008), slug feeding (rapid intake) of the concentrate component of a ration (Maekawa et al., 2002), or competitive interactions (Herlin and Frank, 2007; González et al., 2008). These feeding patterns can lead to metabolic disorders, such as subacute ruminal acidosis, due to excessive consumption of rapidly degradable carbohydrates and lack of effective fiber consumption, often resulting in diarrhea (Krause and Oetzel, 2006: DeVries et al., 2008). It is possible that these feeding behavior patterns develop as a result of learning that occurs early in life. Researchers have recently shown that young dairy heifers exposed to roughage and concentrate in either a top-dressed ration (TDR) or as separate components sort more, consume the concentrate in a slug-feeding pattern, compete more for feed, and have looser fecal consistency than animals presented with the same diet mixed as a TMR (DeVries and von Keyserlingk, 2009a; Greter et al., 2010). If such behavior persists into adult life, then the animal is poorly set up to deal with the challenges of the lactating herd, such as feed bunk competition, low forage rations, and other dietary changes. It may be, therefore, a positive management decision to provide a TMR to dairy cattle from a very young age to ensure easier transitions throughout growth and development of the animal, and to possibly prevent or minimize such undesirable feeding patterns or behaviors from developing.

The objective of this study was to determine how different feeding methods (TDR vs. TMR) may affect the learning of feeding and sorting behavior and feeding competition of growing dairy heifers. Our hypotheses were that heifers previously fed a TMR would distribute their feeding time more evenly throughout the day, sort the new ration less, compete less for feed, maintain a more solid fecal consistency, and continue to grow rapidly due to balanced nutrient intake compared with heifers previously fed a TDR.

\section{MATERIALS AND METHODS}

\section{Animals and Housing}

Thirty-two Holstein dairy heifers were used in this study and were acquired, on loan, from a local commercial dairy operation. The animals were (mean $\pm \mathrm{SD}$ ) $237.2 \pm 21.9 \mathrm{~d}$ old, weighed $264.6 \pm 29.6 \mathrm{~kg}(235.0-294.2$ $\mathrm{kg}$ ), and measured $117.6 \pm 3.2 \mathrm{~cm}(114.4-120.8 \mathrm{~cm})$ high at the withers at the beginning of the experiment. Heifers were given a 12-d adaptation period following arrival at the research facilities. During the adaptation period, dietary components were fed separately to prevent sorting behavior. The heifers were housed in groups of 4 in 8 pens in the heifer research barn at the University of Guelph, Kemptville Campus (Kemptville, Ontario, Canada) and were managed according to the guidelines set by the Canadian Council on Animal Care (1993). Use of animals was approved by the University of Guelph's animal care committee (AUP\#08R011). The pens, located in a naturally ventilated cold barn, consisted of an indoor sawdust-bedded pack area (3.6 $\mathrm{m} \times 10.9 \mathrm{~m})$ and an outdoor concrete run $(3.6 \mathrm{~m} \times$ $16.4 \mathrm{~m}$ ). Bedding material was replenished as needed. Feed bunks were located along the front of each pen and measured $1.35 \mathrm{~m}$ in length, allowing for $0.34 \mathrm{~m}$ of open bunk space per animal. There were no head-gates or vertical barriers used at the feed bunk. The animals were given ad libitum access to feed. Orts were cleaned out of the feed bunks at $1030 \mathrm{~h}$ each day, with new feed delivered once daily at $1200 \mathrm{~h}$. Water was available ad libitum through a water bowl in each pen. Heifers were also given ad libitum access to trace mineral salt blocks (Windsor TM Stock Salt, The Canadian Salt Company Limited, Pointe-Claire, QC, Canada).

\section{Experimental Design and Diets}

Heifers were divided into 8 groups of 4 (balanced on weight and age upon arrival to the facility) and exposed to 1 of 2 dietary treatments for $13 \mathrm{wk}$, according to Greter et al. (2010). The treatment diets were 1) TMR and 2) TDR. The initial treatment diets both contained (on a DM basis) $65 \%$ grass/alfalfa haylage and $35 \%$ of a textured concentrate. Immediately following the 13 -wk period, all pens were switched to an unfamiliar TMR for an additional $7 \mathrm{wk}$. This ration was formulated to allow for an ADG of $1.0 \mathrm{~kg} / \mathrm{d}$ (NRC, 2001). Heifers remained in the same pens with the same group of individuals. The TMR was prepared daily in a mixer wagon and manually weighed into the feed bunk in each pen. The amount of feed offered was adjusted daily to ensure 5 to $10 \%$ orts. The actual orts averaged $5.6 \pm 3.4 \%$ DM of the offered feed over the $7 \mathrm{wk}$ while heifers were on the unfamiliar TMR. The ingredient and chemical composition of the ration is given in Table 1 .

\section{Experimental Measurements}

Group intakes were recorded daily throughout the 7 wk of the study by weighing the amount of feed offered and the amount of feed refused. These data were used to calculate daily DMI $(\mathrm{kg} / \mathrm{d})$ on a pen basis. Heifers were weighed and measured on the same weekday at the same time every 2 wk to measure weight gain and 
Table 1. Ingredient and chemical composition (mean \pm SD) of the treatment diet

\begin{tabular}{lc}
\hline Composition & Value \\
\hline Ingredient, \% of DM $^{\text {Corn silage }}{ }^{1}$ & \\
Grass/alfalfa haylage $^{2}$ & 56.1 \\
High moisture corn $^{3}$ & 21.0 \\
Mineral premix $^{4}$ & 21.0 \\
Chemical composition & 1.9 \\
DM, \% & \\
OM, \% of DM & $52.1 \pm 1.4$ \\
CP, \% of DM & $92.9 \pm 0.2$ \\
ADF, \% of DM & $13.7 \pm 0.6$ \\
NDF, \% of DM & $25.6 \pm 1.0$ \\
NFC, \% of DM & $37.8 \pm 1.2$ \\
Starch, \% of DM & $39.0 \pm 1.3$ \\
\hline
\end{tabular}

${ }^{1}$ Chemical composition of corn silage (DM basis) was $8.2 \pm 0.0 \% \mathrm{CP}$, $21.7 \pm 0.9 \% \mathrm{ADF}$, and $37.0 \pm 0.9 \% \mathrm{NDF}$.

${ }^{2}$ Chemical composition of grass/alfalfa haylage (DM basis) was $17.5 \pm$ $0.6 \% \mathrm{CP}, 33.6 \pm 0.5 \% \mathrm{ADF}$, and $47.3 \pm 1.5 \% \mathrm{NDF}$.

${ }^{3}$ Chemical composition of high moisture corn (DM basis) was $8.8 \pm$ $0.1 \% \mathrm{CP}, 3.7 \pm 0.1 \% \mathrm{ADF}$, and $12.6 \pm 0.2 \% \mathrm{NDF}$.

${ }^{4}$ Supplied by Rooney Feeds Ltd. (Kemptville, ON, Canada), containing (on as-is basis): $14.0 \%$ calcium, $7.8 \%$ sodium, $6.5 \%$ phosphorus, $2.3 \%$ potassium, $1.0 \%$ magnesium, $0.28 \%$ sulfur, $0.16 \%$ lasalocid sodium, 5,760 mg/ $\mathrm{kg}$ iron, 4,000 mg/ $\mathrm{kg}$ zinc, 3,200 mg/ $\mathrm{kg}$ manganese, $980 \mathrm{mg} / \mathrm{kg}$ copper, $500 \mathrm{mg} / \mathrm{kg}$ fluorine, $80 \mathrm{mg} / \mathrm{kg}$ iodine, $20 \mathrm{mg} / \mathrm{kg}$ cobalt, 320,000 IU $/ \mathrm{kg}$ vitamin $\mathrm{A}, 48,000 \mathrm{IU} / \mathrm{kg}$ vitamin $\mathrm{D}_{3}$, and 800 $\mathrm{IU} / \mathrm{kg}$ vitamin $\mathrm{E}$.

${ }^{5}$ Values were obtained from chemical analysis of TMR samples. OM $=$ $100-\%$ ash. $\mathrm{NFC}=100-(\% \mathrm{CP}+\% \mathrm{NDF}+\%$ fat $+\%$ ash $)$.

growth (height). Additionally, animals were fecal scored for consistency of feces twice weekly using a scale from 1 (liquid) to 4 (solid; Ireland-Perry and Stallings, 1993).

Feeding behavior and feeding competition were monitored using time-lapse video equipment. Feeding time and social aggression at the feed bunk were recorded continuously for all $7 \mathrm{~d}$ of each recording week: wk 1,4 , and 7 of the study. Animals were recorded using 1 video camera (Panasonic WV-BP330, Osaka, Japan) per 2 pens, a time-lapse video cassette recorder (Panasonic AG-6740), and a video multiplexer (Panasonic WJ-FS 616 ). Video cameras were located $3.2 \mathrm{~m}$ above the feed bunk between 2 pens. Red lights (100 W), hung adjacent to the cameras, were used to facilitate recording at night. Individual animals were identified within each pen with unique neck collars.

The amount of time spent feeding during all $7 \mathrm{~d}$ of each recording week was scored for individual heifers from video using instantaneous scan sampling every 10 min. For each scan, an animal was recorded as feeding when its head was completely past the feed rail and over the feed. These scans were then used to calculate the total time spent feeding by multiplying the number of scans by 10 (Endres et al., 2005). Time spent feeding was then calculated for each heifer for each day of the recording weeks $(\mathrm{min} / \mathrm{d})$. Additionally, to detect changes in the diurnal pattern of feed bunk attendance, these scans were used to calculate the percentage of heifers at the feed bunk over the course of each 24-h period. Based on these diurnal patterns, we also calculated feeding time for each heifer during the 120-min period (peak feeding time) following the delivery of feed when feeding activity was highest.

Feeding competition, recorded as displacements from the feed bunk while feeding, was measured on d 2, 4, and 6 of each recording week. A displacement was noted when a butt or a push from the actor (instigator) resulted in the complete withdrawal of the reactor's head from beneath the feed rail (DeVries et al., 2004). These observations were used to calculate, according to DeVries et al. (2004), an agonistic interaction success rate (AISR) for each individual heifer. A successful interaction occurs when one heifer (dominant) successfully manages to completely displace another (subdominant) from the feed bunk. The heifers were classed as being either above or below the focal animal in rank. The AISR was calculated as follows: number of individuals subdominant to focal heifer/(number of individuals dominant to focal heifer + number of individuals subdominant to focal heifer) $\times 100 \%$.

\section{Feed Sampling and Analysis}

A representative sample of the ration was collected for particle size separation at feed delivery each day during the recording weeks. Orts samples, for particle size separation, were taken from each feed bunk at the end of each recording day. Samples of the TMR and orts from each pen were taken twice weekly throughout the experiment for DM and chemical analysis, as well as to determine NDF intakes. Samples of the dietary components were also taken once a week for DM and chemical analysis. Duplicate samples of forage components were taken during the recording weeks to allow for particle size analysis. All samples were immediately frozen at $-20^{\circ} \mathrm{C}$ until they were further analyzed.

Samples for particle size separation were separated using the 3-screen (19, 8, and $1.18 \mathrm{~mm})$ Penn State Particle Separator (PSPS; Kononoff et al., 2003). This separated the samples into 4 fractions: long $(>19 \mathrm{~mm})$, medium $(<19,>8 \mathrm{~mm})$, short $(<8,>1.18 \mathrm{~mm})$, and fine $(<1.18 \mathrm{~mm})$ particles. After separation, the DM of each separated fraction was determined by oven drying at $55^{\circ} \mathrm{C}$ for $48 \mathrm{~h}$. The percentage of each fraction in the ration and forage components is given in Table 2.

Dry matter content of samples taken for chemical analysis was determined by drying samples in a forcedair oven at $55^{\circ} \mathrm{C}$ for $48 \mathrm{~h}$. These samples were then ground to pass through a 1-mm screen (Wiley mill, Arthur H. Thomas Co., Philadelphia, PA). These 
Table 2. Particle size of the ration and dietary forage components $($ mean $\pm \mathrm{SD})$

\begin{tabular}{lcrr}
\hline Particle size $^{1}$ & $\begin{array}{c}\text { Grass/ } \\
\text { alfalfa haylage }\end{array}$ & \multicolumn{1}{c}{$\begin{array}{c}\text { Corn } \\
\text { silage }\end{array}$} & \multicolumn{1}{c}{ Ration $^{2}$} \\
\hline Long & $17.6 \pm 4.3$ & $5.4 \pm 3.4$ & $6.6 \pm 2.4$ \\
Medium & $47.7 \pm 2.3$ & $60.1 \pm 6.1$ & $54.7 \pm 2.4$ \\
Short & $29.4 \pm 0.9$ & $31.0 \pm 8.1$ & $31.6 \pm 1.9$ \\
Fine & $5.3 \pm 1.1$ & $3.5 \pm 1.8$ & $7.1 \pm 0.9$ \\
\hline
\end{tabular}

${ }^{1}$ Particle size determined by Penn State Particle Separator, which has a 19-mm screen (long), 8-mm screen (medium), 1.18-mm screen (short), and a pan (fine).

${ }^{2}$ Chemical composition (DM basis) of long particles was $47.3 \pm 2.3 \%$ $\mathrm{NDF}$ and $5.2 \pm 1.3 \%$ starch, that of medium particles was $37.3 \pm 0.9 \%$ $\mathrm{NDF}$ and $23.5 \pm 0.8 \%$ starch, that of short particles was $34.7 \pm 0.6 \%$ NDF and $22.4 \pm 0.7 \%$ starch, and that of fine particles was $25.4 \pm$ $3.6 \% \mathrm{NDF}$ and $31.0 \pm 2.5 \%$ starch.

samples, plus the dried TMR particle fractions, were sent to Cumberland Valley Analytical Services Inc. (Maugansville, MD) for analysis of DM $\left(135^{\circ} \mathrm{C}\right.$; AOAC, 2000; method 930.15), ash $\left(535^{\circ} \mathrm{C}\right.$; AOAC, 2000; method 942.05), ADF (AOAC, 2000; method 973.18), NDF with heat-stable $\alpha$-amylase and sodium sulfite (Van Soest et al., 1991), CP $(\mathrm{N} \times 6.25$; AOAC 2000; method 990.03; Leco FP-528 Nitrogen Analyzer, Leco, St. Joseph, MI), and starch (Holm et al., 1986).

\section{Calculations and Statistical Analysis}

Sorting was calculated as the actual DMI of each fraction of PSPS, expressed as a percentage of the predicted DMI of that fraction (Leonardi and Armentano, 2003). The actual intake of each individual fraction was calculated as the difference between the DM amount of each fraction in the offered feed and that in the refused feed. The predicted intake for each individual fraction was calculated as the product of the DMI of the total diet multiplied by the DM percentage of that fraction in the offered diet. Values equal to $100 \%$ indicate no sorting, $<100 \%$ indicate selective refusals (sorting against), and $>100 \%$ indicate preferential consumption (sorting for).

Preliminary screening of the data revealed that all dependent variables were normally distributed. For analyses of treatment effects, the pen was considered as the experimental unit. The DMI and sorting behavior data were calculated on a pen basis and averaged by week for the entire experiment. Weight gain and growth were averaged on a pen basis by 2-wk period for the entire experiment. Feeding, social, and lying behavior data were averaged across heifers within each pen and days to create one observation per recording week per pen. Data for feed bunk attendance (\% of heifers feeding) were summarized by hour for each pen on each treatment.
To test whether sorting of the experimental diets occurred, data for each PSPS fraction were averaged across each recording week for each pen and tested for a difference from 100 using $t$-tests within the MIXED procedure of SAS (SAS Institute, 2003). To test for the effect of treatment, all data were analyzed using the MIXED procedure (SAS Institute, 2003) treating week as a repeated measure. The model included the fixed effects of treatment and week and the random effect of pen within treatment. The variance-covariance error structure was compound symmetry, variance components, or heterogeneous compound symmetry, depending upon best fit according to Schwarz's Bayesian information criterion. To test for the effect of treatment on feed bunk attendance patterns, these data were analyzed using the MIXED procedure (SAS Institute, 2003) treating hour as a repeated measure. The model included the fixed effects of treatment and hour and the random effect of pen within treatment. The variance covariance structure was first-order autoregressive, according to best fit using Schwarz's Bayesian information criterion. All values reported are least squares means \pm standard error.

To test the hypothesis that socially subordinate heifers would be most affected in their response to the treatments, measures of weight gain, growth, feeding time, peak feeding time, and fecal score were regressed within treatment on the heifer's AISR using the regression procedure of SAS (SAS Institute, 2003). Only those statistically significant models are shown. Unless presented, there were no time $\times$ treatment interactions. For all analyses, significance was declared at $P \leq 0.05$, and a trend was reported if $0.05<P \leq 0.10$.

\section{RESULTS}

Analysis of the diurnal feed bunk attendance of heifers showed a treatment by hour interaction ( $\mathrm{SE}=$ $0.6, P<0.001$; Figure 1), with a greater percentage of heifers previously fed the TDR present at the feed bunk during the $2 \mathrm{~h}$ after feed delivery (period of peak feeding activity). During the peak feeding period, heifers previously fed the TDR spent more time at the feed bunk than heifers previously fed the TMR (Table 3). Over the whole day, this resulted in a tendency for the heifers previously fed the TDR to have longer feeding times (Table 3 ). The AISR was negatively related to feeding time $\left(\mathrm{y}=-0.3 \mathrm{x}+202.3 ; \mathrm{R}^{2}=0.28, P=0.03\right)$ and tended to be negatively related to peak feeding time $\left(\mathrm{y}=-0.1 \mathrm{x}+29.3 ; \mathrm{R}^{2}=0.23, P=0.06\right)$ for heifers previously fed the TMR, whereas there was no relationship between AISR and feeding time or peak feeding time for heifers previously fed the TDR. The number of displacements, as measured by the number 
Table 3. Intake and behavior measures from growing dairy heifers on experimental treatments ${ }^{1}$

\begin{tabular}{|c|c|c|c|c|}
\hline \multirow[b]{2}{*}{ Item } & \multicolumn{2}{|c|}{ Treatment $^{2}$} & \multirow[b]{2}{*}{ SE } & \multirow[b]{2}{*}{$P$-value } \\
\hline & TMR & TDR & & \\
\hline Feeding time, $\min / \mathrm{d}$ & 186.8 & 198.8 & 4.2 & 0.06 \\
\hline Peak feeding time, ${ }^{3} \mathrm{~min} / \mathrm{d}$ & 25.9 & 40.6 & 3.8 & 0.03 \\
\hline Displacements, no./d & 13.1 & 23.0 & 1.8 & $<0.001$ \\
\hline Peak displacements, ${ }^{3}$ no. $/ \mathrm{d}$ & 3.2 & 8.0 & 0.7 & 0.002 \\
\hline Fecal score & 3.7 & 3.2 & 0.1 & 0.02 \\
\hline DMI, kg/d & 8.9 & 9.1 & 0.3 & 0.6 \\
\hline Weight gain, kg/d & 1.2 & 1.1 & 0.07 & 0.3 \\
\hline
\end{tabular}

${ }^{1}$ Data are averaged across 4 pens (4 heifers/pen) on each treatment.

${ }^{2}$ Heifers were previously fed, on a DM basis, $35 \%$ concentrate fed topdressed (TDR) on or mixed with (TMR) $65 \%$ grass/alfalfa haylage for 13 wk.

${ }^{3}$ Peak feeding activity period $=2$-h period immediately following feed delivery.

of times a heifer was physically displaced from the feed bunk, was greater for animals previously fed the TDR than for those previously fed the TMR, particularly during the period of peak feeding activity (Table 3).

Heifers sorted against long particles $(>19 \mathrm{~mm})$ on both treatments (Table 4). There was, however, no difference in the extent of this sorting between treatments. Animals did not sort for or against medium particles on either treatment (Table 4). Heifers previously fed the TDR tended to sort against short particles, whereas heifers fed the TMR did not sort for or against short particles (Table 4). Heifers previously fed the TDR sorted against fine particles, whereas heifers fed the TMR tended to sort against fine particles (Table 4). As a result, there was a weak tendency for a difference between treatments for sorting of short and fine particles.

Heifers previously fed the TDR had more fluid feces than those fed the TMR (Table 3). Dry matter intake did not differ between treatments (Table 3). Average daily gain was also similar between treatments (Table $3)$.

\section{DISCUSSION}

In support of our hypothesis, we found that heifers previously fed a TMR distributed their feeding time more evenly throughout the day, whereas heifers previously fed a TDR showed a greater peak in feeding activity following feed delivery. Heifers previously fed the TDR spent over $60 \%$ more time at the feed bunk during peak feeding activity, which translated to $12 \%$ more heifers present at the feed bunk. This is similar to what was seen during the first 13 wk of the experiment,

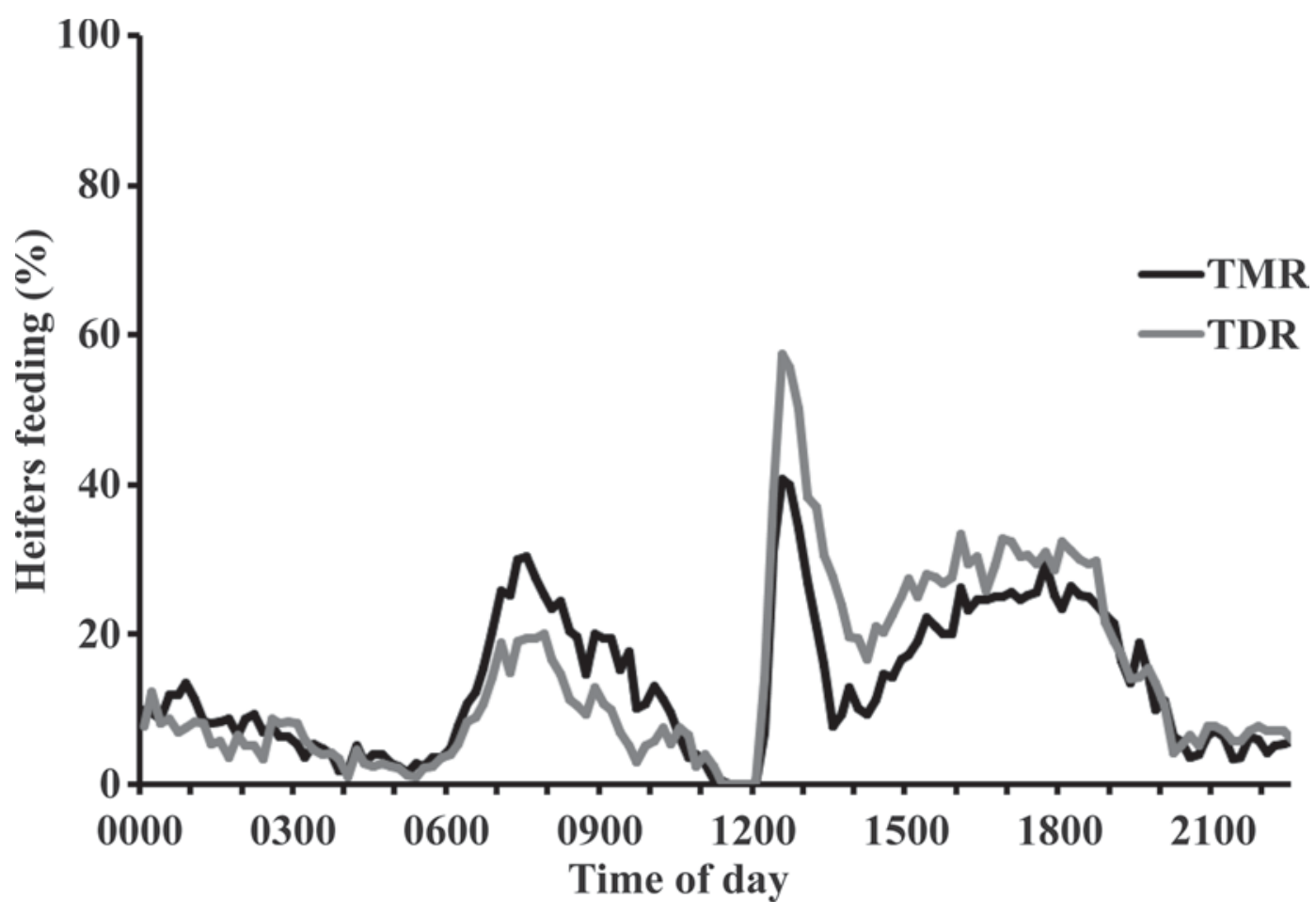

Figure 1. Percentage of heifers present at the feed bunk over a 24-h period (percentage for each 10-min interval during the day) for 2 treatments: 1) heifers previously fed a TMR and 2) heifers previously fed a top-dressed ration (TDR). Data were averaged across $21 \mathrm{~d}$ for 4 pens (4 heifers/pen) per treatment. 
Table 4. Effect of experimental treatments on the sorting (\%) of long, medium, short, and fine particles by growing dairy heifers ${ }^{1}$

\begin{tabular}{|c|c|c|c|c|}
\hline \multirow[b]{2}{*}{ Particle size ${ }^{2}$} & \multicolumn{2}{|c|}{ Treatment $^{3}$} & \multirow[b]{2}{*}{$\mathrm{SE}$} & \multirow[b]{2}{*}{$P$-value } \\
\hline & TMR & TDR & & \\
\hline Long & $91.6^{*}$ & $93.2^{*}$ & 2.1 & 0.6 \\
\hline Medium & 99.9 & 99.9 & 0.2 & 0.9 \\
\hline Short & 100.0 & $99.6^{*}$ & 0.2 & 0.1 \\
\hline Fine & $99.4 \dagger$ & $98.4^{*}$ & 0.3 & 0.1 \\
\hline
\end{tabular}

${ }^{1}$ Sorting $\%=100 \times($ particles size $\mathrm{n}$ DM intake/particle size $\mathrm{n}$ predicted intake). Sorting values equal to $100 \%$ indicate no sorting, $<100 \%$ indicate selective refusals (sorting against), and $>100 \%$ indicate preferential consumption (sorting for). Data are averaged across $21 \mathrm{~d}$ for 4 pens ( 4 heifers/pen) on each treatment.

${ }^{2}$ Particle size determined by Penn State Particle Separator, which has a 19-mm screen (long), 8-mm screen (medium), 1.18-mm screen (short), and a pan (fine).

${ }^{3}$ Heifers were previously fed, on a DM basis, $35 \%$ concentrate fed topdressed on (TDR) or mixed with (TMR) $65 \%$ grass/alfalfa haylage for $13 \mathrm{wk}$.

$* P<0.05 ; \dagger P<0.10$ : Difference in sorting values from $100 \%$.

where heifers fed the TDR spent over $60 \%$ more time at the feed bunk with $15 \%$ more heifers present at the feed bunk during peak feeding activity (Greter et al., 2010). In fact, the diurnal feeding pattern for all heifers was very similar to that seen during the first $13 \mathrm{wk}$ of the experiment, when animals were fed using different feeding methods. It can, therefore, be suggested that the animals had learned to feed in a particular pattern during the first $13 \mathrm{wk}$, and that these animals retained that pattern across the ration change. Furthermore, these feeding patterns persisted through the $7 \mathrm{wk}$ of the experiment, suggesting that the animals had not only learned particular feeding patterns, but that these patterns were continual and may be difficult to alter or extinguish over time. It was likely that, during the first 13 wk of the experiment, heifers fed a TDR were spending more time at the feed bunk during peak feeding activity because of the rapid consumption of the readily available concentrate component of the ration (Greter et al., 2010). As such, it is likely that heifers previously fed the TDR continued to spend more time at the feed bunk during the period of peak feeding activity simply as a result of previous feeding patterns, in which these animals were consuming large amounts of their grain concentrate during this period (Greter et al., 2010). It can be hypothesized that the heifers then learned from and became conditioned to the feeding experience, and, as a result, continued to utilize these feeding patterns when switched to an unfamiliar ration.

We also found, in support of our hypothesis, that the heifers previously fed the TMR competed less for their feed than heifers previously fed the TDR, engaging in half the number of displacements. This translated into these heifers being displaced $40 \%$ more often than heifers fed the TMR during the period of peak feeding activity. Additionally, heifers previously fed the TDR performed a greater percentage of their daily displacements $(35 \%)$ during this period compared with heifers previously fed the TMR (24\%). These results are similar to that seen when heifers were fed using different feeding methods, wherein the heifers fed the TDR performed a greater percentage $(37 \%)$ of their daily displacements during the period of peak feeding activity than heifers fed the TMR (22\%; Greter et al., 2010). It should be noted that stocking density at the feed bunk was not excessive (Longenbach et al., 1999), and that, in a situation of high stocking density, the effects seen here may have been exacerbated (DeVries and von Keyserlingk, 2009b). Interestingly, heifers previously fed the TDR were unaffected by dominance status in their feeding patterns compared with heifers previously fed the TMR, who were affected. This suggests that, despite the fact that all animals were given the same ration using the same feeding method, the motivation to consume the ration remained strong in all heifers previously fed the TDR and that even subordinate animals were motivated to compete openly for feed, particularly during the period of peak feeding. This provides further evidence that a competitive feeding behavior pattern became habitual in these animals. Habits are learned behaviors that become resistant to extinction or alteration by changes in outcome (Adams and Dickinson, 1981). The competition seen in heifers fed the TDR during the first 13 wk would have resulted in occasional rewards of larger amounts of concentrate (because the concentrate component was more readily available than in the TMR) when interactions were successful. Research has shown that intermittent reinforcement is known to induce habit formation in rats (Wojnicki et al., 2007). As such, this competitive behavior would be intermittently reinforced and this may offer further explanation as to why the behavior did not extinguish across the ration change and became habitual (Theios, 1962).

In further support of our hypothesis, heifers previously fed the TDR continued to exhibit lower, loose fecal scores throughout the course of the experiment compared with heifers previously fed the TMR. These fecal scores were similar to that observed during the first part of the experiment (Greter et al., 2010). We can speculate that the looser feces were the result of rumen fermentation problems, possibly because of the continuation of slug feeding patterns. Slug feeding of concentrate or of TMR may result in large postprandial decreases in rumen $\mathrm{pH}$ and cause diarrhea (Nocek, 1997; Kleen et al., 2003; Krause and Oetzel, 2006). Heifers previously consuming a TMR from a young age, conversely, demonstrated a more balanced feeding pat- 
tern throughout the day and had a more normal fecal consistency. The continuation of this through the ration change indicates that these animals were conditioned to this feeding pattern.

Contrary to our hypothesis, the sorting behavior of the heifers was similar between treatment groups after the dietary change. It was expected that heifers previously fed the TDR would actively sort for the short particle fraction of the ration, as this fraction primarily contained the concentrate component of the ration, something that these animals had previously sorted and competed heavily for during the period of peak feeding activity (Greter et al., 2010). Alternatively, given that the difference in sorting between feeding methods had disappeared by the final week of the first $13 \mathrm{wk}$ of the experiment (Greter et al., 2010), it may not be surprising that the sorting behavior was similar for all heifers when they were changed to the new ration. There also was no difference in DMI between treatments, which could be expected because all animals were fed the same ration and no difference in DMI had been observed during the first $13 \mathrm{wk}$ of the experiment (Greter et al., 2010).

Further, contrary to our hypothesis, there was no difference in ADG between treatments. However, the lack of difference in gain between treatments is surprising, because the fecal scores were different between treatments. Similar results in gain were also seen during the first $13 \mathrm{wk}$ of the experiment (Greter et al., 2010), and it was speculated there that these animals may have been able to adapt to depressing conditions and balance resources to maintain gain, something that has been known to occur in adult animals experiencing similar challenges (O'Grady et al., 2008). However, it is hypothesized that this ability to adapt may be short term, and that the heifers previously fed a TDR would not be able to maintain, in the long term, a similar ADG to those fed the TMR. Results from this experiment show otherwise, suggesting that the fecal consistency difference was not large enough to indicate any major physiological changes across treatments.

Overall, this research provides interesting insight into the learning of behavioral patterns in young dairy heifers. Further research in this area is needed to assist in the development of management protocols that would help to cultivate the learning of desirable behavior and prevent detrimental feeding patterns from developing. It still needs to be determined how long learned feeding patterns may persist in the life of the animal. In addition, it is unknown if these behaviors could be extinguished or altered over time or through further learning experiences, particularly when heifers enter the lactating herd and are presented with the challenges of frequent ration changes, group changes, and production stress. Furthermore, the persistence of these undesirable behaviors may put the cow at a disadvantage later in life if she should lose the ability to be flexible in her feeding behavior and no longer able to adapt readily to changes in situation or physiological state (Kyriazakis et al., 1999). Future research on the flexibility of feeding behavior and the possible effect on the internal state of the animal over time would be helpful in determining the long-term effects of feeding patterns and habits. It was not possible to measure rumen $\mathrm{pH}$ in this study. Thus, further research is needed to determine if the feeding patterns that developed truly did disrupt normal rumen fermentation. Finally, the lack of sorting difference following the ration change was quite surprising. Further research on the learning of sorting behavior is needed, particularly considering when and how this behavior develops, as it would appear that feeding method has little effect on the development of sorting behavior in prepubertal dairy heifers.

\section{CONCLUSIONS}

Long-term exposure to these feeding methods affected the learning of feeding and competitive behavior in growing dairy heifers. The diurnal feeding activity pattern, increased feed bunk competition, and less solid fecal consistency suggest that heifers previously fed a TDR had developed undesirable and possibly detrimental behavioral patterns. Alternatively, it can be concluded that feeding a TMR from a young age to replacement dairy heifers results in long-term behavioral patterns that promote a more even diurnal feeding pattern, minimize feed bunk competition, and promote a more solid fecal consistency, thus improving the overall welfare of these animals.

\section{ACKNOWLEDGMENTS}

We thank the staff and students at the University of Guelph, Kemptville Campus Dairy Education and Research Centre. In particular, we thank Megan Bruce, Albert Koekkoek, Emily Miller-Cushon, and Hauke Timm for their help with the project. We would like to thank Arnold Schouten for the use of the heifers during the course of this experiment. Angela Greter was supported by a Natural Sciences and Engineering Research Council of Canada (NSERC) Post-Graduate Scholarship. This project was funded by an NSERC Collaborative Research and Development Grant with the Dairy Farmers of Canada and received support from the Ontario Ministry of Agriculture, Food and Rural Affairs. 


\section{REFERENCES}

Adams, C. D., and A. Dickinson. 1981. Instrumental responding following reinforce devaluation. Q. J. Exper. Psychol. Comp. Physiol. Psychol. 33:109-122.

AOAC. 2000. Official Methods of Analysis. Vol. I. 17th ed. Association of Official Analytical Chemists International, Arlington, VA.

Arnold, G. W., and R. A. Maller. 1977. Effects of nutritional experience in early and adult life on the performance and dietary habits of sheep. Appl. Anim. Ethol. 3:5-26.

Burritt, E. A., and F. D. Provenza. 1990. Food aversion learning in sheep: Persistence of conditioned taste aversions to palatable shrubs (Cercocarpus montanus and Amelanchier alnifolia). J. Anim. Sci. 68:1003-1007.

Canadian Council on Animal Care. 1993. Guide to the Care and Use of Experimental Animals. Vol. 1. E. D. Olfert, B. M. Cross, A. A. McWilliam, ed. CCAC, Ottawa, Canada.

DeVries, T. J., F. Dohme, and K. A. Beauchemin. 2008. Repeated ruminal acidosis challenges in lactating dairy cows at high and low risk for developing acidosis: Feed sorting. J. Dairy Sci. 91:39583967.

DeVries, T. J., and M. A. G. von Keyserlingk. 2009a. Feeding method affects the feeding behavior of growing dairy heifers. J. Dairy Sci. 92:1161-1168.

DeVries, T. J., and M. A. G. von Keyserlingk. 2009b. Competition for feed affects the feeding behavior of growing dairy heifers. J. Dairy Sci. 92:3922-3929.

DeVries, T. J., M. A. G. von Keyserlingk, and D. M. Weary. 2004. Effect of feeding space on the inter-cow distance, aggression, and feeding behavior of free-stall housed lactating dairy cows. J. Dairy Sci. 87:1432-1438.

Endres, M. I., T. J. DeVries, M. A. G. von Keyserlingk, and D. M. Weary. 2005. Effect of feed barrier design on the behavior of loosehoused lactating dairy cows. J. Dairy Sci. 88:2377-2380.

González, L. A., A. Ferret, X. Manteca, J. L. Ruíz-de-la-Torre, S Calsamiglia, M. Devant, and A. Bach. 2008. Performance, behavior, and welfare of Friesian heifers housed in pens with two, four, and eight individuals per concentrate feeding place. J. Anim. Sci. 86:1446-1458.

Greter, A. M, K. E. Leslie, G. J. Mason, B. W. McBride, and T. J. DeVries. 2010. Effect of feeding method on the behavior and growth of dairy heifers. J. Dairy Sci. 93:1668-1676.

Herlin, A. H., and B. Frank. 2007. Effects of protective gates at concentrate feed stations on behaviour and production in dairy cows: A brief note. Appl. Anim. Behav. Sci. 103:167-173.

Holm, J., I. Bjorck, A. Drews, and N. G. Asp. 1986. A rapid method for the analysis of starch. Starch/Die Starke 38:224-226.

Ireland-Perry, R. L., and C. C. Stallings. 1993. Fecal consistency as related to dietary composition in lactating Holstein cows. J. Dairy Sci. 76:1074-1082.

Kleen, J. L., G. A. Hooijer, J. Rehage, and J. P. Noordhuizen. 2003 Subacute ruminal acidosis (SARA): A review. J. Vet. Med. A 50:406-414.
Kononoff, P. J., A. J. Heinrichs, and D. R. Buckmaster. 2003. Modification of Penn State forage and total mixed ration particle separator and the effects of moisture content on its measurements. J. Dairy Sci. 86:1858-1863.

Krause, K. M., and G. R. Oetzel. 2006. Understanding and preventing subacute ruminal acidosis in dairy herds: A review. Anim. Feed Sci. Technol. 126:215-236.

Kyriazakis, I., B. J. Tolkamp, and G. Emmans. 1999. Diet selection and animal state: An integrative framework. Proc. Nutr. Soc. $58: 765-772$.

Leonardi, C., and L. E. Armentano. 2003. Effect of quantity, quality, and length of alfalfa hay on selective consumption by dairy cows. J. Dairy Sci. 86:557-564

Longenbach, J. I., A. J. Heinrichs, and R. E. Graves. 1999. Feed bunk length requirements for Holstein dairy heifers. J. Dairy Sci. 82:99-109.

Maekawa, M., K. A. Beauchemin, and D. A. Christensen. 2002. Effect of concentrate level and feeding management on chewing activities, saliva production, and ruminal $\mathrm{pH}$ of lactating dairy cows. J. Dairy Sci. 85:1165-1175.

NRC. 2001. Nutrient Requirements for Dairy Cattle. Natl. Acad. Sci. Washington, DC.

Nocek, J. E. 1997. Bovine acidosis: Implications on laminitis. J. Dairy Sci. 80:1005-1028.

Nolte, D. L., F. D. Provenza, and D. F. Balph. 1990. The establishment and persistence of food preferences in lambs exposed to selected foods. J. Anim. Sci. 68:998-1002.

O'Grady, L., M. L. Doherty, and F. J. Mulligan. 2008. Subacute ruminal acidosis (SARA) in grazing Irish dairy cows. Vet. J. 176:44-49.

Provenza, F. D. 1995. Postingestive feedback as an elementary determinant of food preference and intake in ruminants. J. Range Manage. 48:2-17.

Provenza, F. D., and D. F. Balph. 1987. Diet learning by domestic ruminants-Theory, evidence and practical implications. Appl. Anim. Behav. Sci. 18:211-232.

Ralphs, M. H., D. Graham, and L. F. James. 1994. Social facilitation influences cattle to graze locoweed. J. Range Manage. 47:123126

SAS Institute. 2003. User's Guide: Statistics. Version 9.1.3 ed. SAS Institute Inc., Cary, NC.

Theios, J. 1962. The partial reinforcement effect sustained through blocks of continuous reinforcement. J. Exp. Psychol. 64:1-6.

Van Soest, P. J., J. B. Robertson, and B. A. Lewis. 1991. Methods for dietary fiber, neutral detergent fiber and nonstarch polysaccharide in relation to animal nutrition. J. Dairy Sci. 74:3583-3597.

Wojnicki, F. H. E., J. G. Stine, and R. L. W. Corwin. 2007. Liquid sucrose bingeing in rats depends on the access schedule, concentration and delivery system. Physiol. Behav. 92:566-574. 